\title{
Research on the coordination degree of ecological protection and high-quality development of urban agglomerations in the Yellow River Basin
}

\author{
Jinhui Zhao ${ }^{1}$, Yunlong Bai ${ }^{1, *}$, Chao Zhang ${ }^{2}$, Jiawei $\mathrm{He}^{1}$ and Siyuan $\mathrm{Li}^{1}$ \\ ${ }^{1}$ College of Mechanical and Power Engineering, Zhengzhou University, Zhengzhou 450001, China; \\ ${ }^{2}$ School of Chemical Engineering, Zhengzhou University, Zhengzhou 450001, China
}

\begin{abstract}
The Yellow River Basin is ecologically fragile, the relationship between water and sand is unbalanced and water resources are scarce. This paper takes the urban agglomerations in the Yellow River Basin as the research object, based on the guidelines for the coordinated promotion of ecological protection and high-quality development in the basin, and uses the entropy weight method and the coefficient of variation method as the means to establish a quantitative evaluation system for coordinated development. The degree of synergy is between ecological protection and high-quality development of the urban agglomerations from the time dimension and the space dimension, and we give the optimization directions. The results show that the degree of synergy among urban agglomerations in the river basin is steadily increasing, but there are significant spatial differences in the degree of coordination of ecological protection and high-quality development of the urban agglomerations and the development index of its subsystems. The degree of synergy generally presents a cascade distribution pattern that gradually decreases from east to west and from downstream to upstream. The ecological destruction, economic fluctuations and water waste of the river basin urban agglomeration are the main factors hindering the improvement of synergy.
\end{abstract}

\section{Introduction}

The Yellow River is one of the birthplaces of Chinese civilization and an important ecological barrier and economic belt in China, the importance of which is beyond doubt.

At the symposium on ecological protection and highquality development of the Yellow River Basin, General Secretary $\mathrm{Xi}$ Jinping clearly stated that "ecological protection and high-quality development of the Yellow River Basin are as significant a national strategy as the integrated development of the Yangtze River Delta, the construction of the Guangdong-Hong Kong-Macao Greater Bay Area, the development of the Yangtze River Economic Belt, and the coordinated development of Beijing-Tianjin-Hebei ${ }^{[1]}$." The need for ecological protection to be promoted simultaneously with highquality development was emphasized in the conference, which called for the need to change the traditional crude economic development model and to effectively implement the ecological protection and high-quality development strategy of the Yellow River basin with ecological culture and green development as the grip.

\section{Current status of research}

The Yellow River Basin is an ecological corridor connecting the North China Plain, the Loess Plateau and the Qinghai-Tibet Plateau. Its resources are highly enriched and well combined, and it is an important raw material, chemical, energy and industrial base in China. ${ }^{[2]}$ Therefore, it is of great significance to analyze the synergy degree of ecological protection and high-quality development of the urban agglomeration in the Yellow River Basin. Shao Peng ${ }^{[3]}$ made a specific analysis of ecological protection and high-quality development in the Yellow River basin at three levels: current situation combing, strategic interpretation and response measures, and compared three aspects of high-quality development, protection and governance and cultural heritage of the basin. Ren Baoding ${ }^{[4]}$ proposed that the realization paths of the new model of ecological protection and high-quality development in the middle reaches of the Yellow River basin is as follows: improving ecological protection and governance mechanism, enhancing top-level design, building a new development pattern, innovating management system and deepening reform. Ma Haitao [5] argued that the Yellow River basin should enhance the radiation of core cities to urban agglomerations, driving and influencing the high-quality development of the whole basin through the high-quality development of urban agglomerations as a whole. Zhao Rongqin ${ }^{[6]}$ argues that ecological protection is the protection of "land", while high-quality development is the development of "people", and the key to promote the high-quality development of

\footnotetext{
*Corresponding author: 1355786923@qq.com
} 
the river basin is to correctly deal with the relationship between people and land. In different regions, the natural environment and human activities interact with each other in different intensity, scale and manner, constituting different "human-land relationship territorial systems" [710].

Therefore, in evaluating the synergistic level of ecological protection and high-quality development of urban agglomerations in the Yellow River Basin, the natural environment of the basin interacting with human activities should be analyzed in four dimensions: ecological environment, economic development, humanwater relationship and people's well-being. Most of the current studies have focused on the overall ecological protection and high-quality development of the Yellow River Basin. Previous studies have been unable to delineate the coordinated characteristics of ecological protection and high-quality development of each urban cluster in the Yellow River Basin in detail. On this basis, this paper organically combines the entropy weight method and the coefficient of variation method to conduct an in-depth research analysis on the synergy degree of ecological protection and high-quality development of urban clusters in the basin.

\section{Model construction}

The model of ecological protection and high-quality development in the Yellow River Basin is based on the entropy weight method and the coefficient of variation. The entropy weight method uses the statistical properties of the selected elements to determine the weights, which avoids the subjective and arbitrary weighting of the elements, which is used to measure the level of ecological protection and high-quality development. The coefficient of variation is used to measure the variation degree of each element value in the data, which can eliminate the effect of different units or averages on the comparison of the degree of variation of two or more data, and the specific steps are described in the literature. ${ }^{[11-12]}$

The synergistic quantification system of ecological protection and high-quality development in the Yellow River Basin is reflected in the direction of each element's influence on the subsystem in four aspects: ecological environment, economic development, human-water relationship and people's well-being, and the actual situation of the study area and the characteristics of the elements need to be considered at the same time. The accuracy of the quantitative assessment results is closely related to the scientific and reasonable weighting of the elements, and the weighting, as a reflection of the importance of each element, should be objective and accurate. In this paper, entropy weight method and coefficient of variation method are used to determine the weights of each element, and then the arithmetic mean of the weights derived from the two methods is used to determine the final weights. The index system of ecological protection and high-quality development of the Yellow River Basin and the calculation results of the weight of each element are shown in Table 1.
Table1. Quantitative index system of ecological protection and high-quality development of the Yellow River Basin and calculation results of the weights of each element

\begin{tabular}{|c|c|c|}
\hline $\begin{array}{l}\text { Subsystem } \\
\text { layer }\end{array}$ & Element layer & $\begin{array}{c}\text { Weig } \\
\text { hts }\end{array}$ \\
\hline \multirow{8}{*}{ ecosystem } & Forest cover rate & 0.018 \\
\hline & $\begin{array}{l}\text { Newly added water and soil erosion } \\
\text { control area this year }\end{array}$ & 0.041 \\
\hline & $\begin{array}{l}\text { Proportion of wetland area in } \\
\text { jurisdiction }\end{array}$ & 0.041 \\
\hline & Park green area per capita & 0.032 \\
\hline & Annual average PM2.5 & 0.027 \\
\hline & Fertilizer application rate & 0.031 \\
\hline & $\begin{array}{l}\text { Comprehensive utilization rate of } \\
\text { solid waste }\end{array}$ & 0.019 \\
\hline & $\begin{array}{l}\text { Harmless treatment rate of domestic } \\
\text { garbage }\end{array}$ & 0.014 \\
\hline \multirow{9}{*}{$\begin{array}{c}\text { economic } \\
\text { development }\end{array}$} & GDP per capita & 0.02 \\
\hline & Per capita fiscal revenue & 0.026 \\
\hline & Economic volatility & 0.047 \\
\hline & Contribution rate of tertiary industry & 0.041 \\
\hline & R\&D investment intensity & 0.035 \\
\hline & $\begin{array}{c}\text { Number of R\&D personnel per } \\
10,000 \text { employees }\end{array}$ & 0.034 \\
\hline & $\begin{array}{l}\text { Number of granted invention patents } \\
\text { per } 10,000 \text { people }\end{array}$ & 0.038 \\
\hline & Foreign trade dependence & 0.046 \\
\hline & Foreign direct investment dependence & 0.042 \\
\hline \multirow{8}{*}{$\begin{array}{l}\text { Human-water } \\
\text { relationship }\end{array}$} & Water resources per capita & 0.069 \\
\hline & $\begin{array}{l}\text { Comprehensive production capacity } \\
\text { of water supply }\end{array}$ & 0.036 \\
\hline & $\begin{array}{l}\text { Wastewater discharge per } 10,000- \\
\text { yuan GDP }\end{array}$ & 0.02 \\
\hline & Urban sewage treatment rate & 0.012 \\
\hline & $\begin{array}{c}\text { Proportion of surface water quality } \\
\text { standards I-III }\end{array}$ & 0.021 \\
\hline & $\begin{array}{l}\text { Water consumption per 10,000-yuan } \\
\text { GDP }\end{array}$ & 0.031 \\
\hline & $\begin{array}{c}\text { Water resources development and } \\
\text { utilization rate }\end{array}$ & 0.044 \\
\hline & Water penetration rate & 0.012 \\
\hline \multirow{10}{*}{$\begin{array}{l}\text { People's } \\
\text { happiness }\end{array}$} & Urban-rural income ratio & 0.019 \\
\hline & Engel coefficient & 0.017 \\
\hline & Urban registered unemployment rate & 0.01 \\
\hline & Urbanization rate & 0.014 \\
\hline & Aging ratio & 0.015 \\
\hline & Education expenditure per capita & 0.014 \\
\hline & Internet penetration rate & 0.022 \\
\hline & Urban road area per capita & 0.033 \\
\hline & $\begin{array}{l}\text { Proportion of urban and rural } \\
\text { residents with basic pension insurance }\end{array}$ & 0.027 \\
\hline & $\begin{array}{l}\text { Health technicians per thousand } \\
\text { people }\end{array}$ & 0.03 \\
\hline
\end{tabular}




\section{Analysis of results}

\subsection{Analysis of the development of synergy in urban agglomerations}

According to the calculation results of the urban agglomerations' synergy degree in the Yellow River basin from 2009 to 2018 (Figure 1), the synergy degree of ecological protection and high-quality development of urban agglomerations in the basin generally shows ladder distribution pattern of gradual decrease from east to west and from downstream to upstream. Among the city clusters in the middle and lower reaches, the synergy degree of Guanzhong Plain City Cluster and Jinzhong City Cluster is significantly lower than that of Shandong City Cluster along the Yellow River in the east and HubaoEgyu City Cluster in the west, while the synergy degree of Central City Cluster is in the middle.

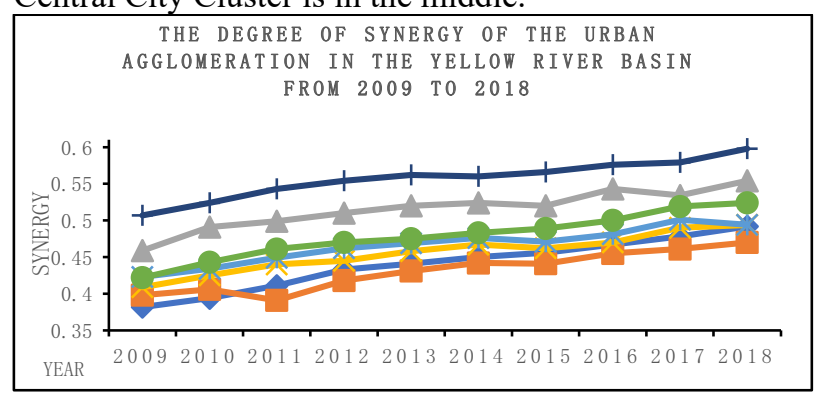

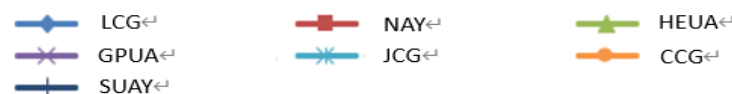

$$
\begin{aligned}
& \text { Ps. Lanxi City Group-LCG } \\
& \text { Ningxia Agglomeration along the Yellow River-NAY } \\
& \text { Hubao Eyu Urban Agglomeration-HEUA } \\
& \text { Guanzhong Plain Urban Agglomeration-GPUA } \\
& \text { Jinzhong City Group-JCG } \\
& \text { Central Plains City Group-CCG }
\end{aligned}
$$

Fig 1. The degree of coordination of the urban agglomeration in the Yellow River Basin from 2009 to 2018

\subsection{Analysis of subsystem synergy development}

According to the calculation results of the subsystems' synergy degree in the Yellow River Basin urban agglomerations in 2018 (Table 2), there are significant spatial differences in the synergy degree of ecological protection and high-quality development in both the Yellow River Basin urban agglomerations and subsystems. With a significant gap, the synergy degree score of Shandong along the Yellow River urban agglomeration is 0.128 higher than that of Ningxia along the Yellow River urban agglomeration. Among the four subsystems of ecological environment, economic development, humanwater relationship and people's well-being, the development index of economic development subsystem has the largest difference, the development index of humanwater relationship and ecological environment subsystem has relatively small difference, and the development index of people's well-being subsystem has the middle difference. Furthermore, the first place of each development index is $0.028,0.085,0.024$ and 0.045 higher than the seventh place respectively.

City clusters with high level of synergistic development also have weaknesses, while those with low level of synergistic development also have strengths. The Shandong City Cluster along the Yellow River, which ranks first in terms of synergy, has a lower ecological environment and human-water relationship development index than the upstream city clusters. The Hubao-Eyu City Cluster, which ranks second in terms of synergy, has a constraint in terms of economic development index; the Central Plains City Cluster, Guanzhong Plain City Cluster and Jinzhong City Cluster, which rank third, fourth and fifth in terms of synergy, need to improve their ecological environment and human-water relationship development index, while the Guanzhong Plain City Cluster and Jinzhong City Cluster still need to strengthen infrastructure construction and enhance people's sense of happiness. The ecological environment and human-water relationship development index of Lanxi city cluster, which is ranked sixth in the overall ranking, is high, which can make use of its ecological advantages to protect the ecology, nurture water, and create more ecological products to drive economic and livelihood development. However, Ningxia City Cluster along the Yellow River, which ranks the lowest overall, is in the bottom two in terms of ecological environment, economic development and human-water relationship index. It has a quantity of shortcomings like lacking of advantageous items, water shortage, ecological constraints and the highest environmental sensitivity, so its synergistic development path needs more attention and support from the Yellow River Basin and even the whole country.

Table2. The calculation results of the coordination degree of subsystems in the Yellow River Basin urban agglomeration in 2018

\begin{tabular}{|c|c|c|c|c|c|}
\hline $\begin{array}{c}\text { Grou } \\
\mathrm{p}\end{array}$ & $\begin{array}{c}\text { Syner } \\
\text { gy }\end{array}$ & $\begin{array}{c}\text { Ecological } \\
\text { Environm } \\
\text { ent Index }\end{array}$ & $\begin{array}{c}\text { Economic } \\
\text { Developm } \\
\text { ent Index }\end{array}$ & $\begin{array}{c}\text { Human } \\
\text {-Water } \\
\text { Relatio } \\
\text { ns } \\
\text { Index }\end{array}$ & $\begin{array}{c}\text { People's } \\
\text { Happine } \\
\text { ss Index }\end{array}$ \\
\hline LCG & 0.492 & 0.137 & 0.105 & 0.153 & 0.097 \\
\hline NAY & 0.470 & 0.109 & 0.118 & 0.127 & 0.116 \\
\hline $\begin{array}{c}\text { HEU } \\
\text { A }\end{array}$ & 0.554 & 0.133 & 0.138 & 0.157 & 0.126 \\
\hline $\begin{array}{c}\text { GPU } \\
\text { A }\end{array}$ & 0.494 & 0.122 & 0.130 & 0.133 & 0.109 \\
\hline JCG & 0.494 & 0.111 & 0.152 & 0.124 & 0.106 \\
\hline CCG & 0.524 & 0.111 & 0.160 & 0.133 & 0.119 \\
\hline $\begin{array}{c}\text { SUA } \\
\text { Y }\end{array}$ & 0.598 & 0.125 & 0.190 & 0.140 & 0.142 \\
\hline
\end{tabular}

\subsection{Evaluation of the development level of urban agglomeration synergy}

According to the classification standard of the coordination degree, combined with the coordination degree of the urban agglomerations in the Yellow River Basin (Table 3), the coordination degree of each city is divided. In 2009, only the urban agglomeration along the Yellow River in Shandong had a degree of synergy greater than 0.5 , which was in a state of "close to synergy". Most of the other urban agglomerations are in a state of "on the 
verge of imbalance", and the western urban agglomeration and the urban agglomerations along the Yellow River in Ningxia are in a state of "slight imbalance"; in 2012, the Hubao-Eyu urban agglomeration has also entered a state of "close to synergy"; by 2018,the Shandong Peninsula urban agglomeration, the Central China urban agglomeration, Hubao-Eyu urban agglomeration have reached a state of "close to synergy", and the remaining four urban agglomerations are also about to reach a state of "close to synergy". On the whole, the level of coordinated development of various urban agglomerations is steadily improving, and the difference of coordinated development of various urban agglomerations is gradually disappearing.

Table3. Analysis of coordination degree of ecological protection and high-quality development of urban agglomerations in the Yellow River Basin

\begin{tabular}{|c|c|c|c|c|c|c|c|c|c|c|}
\hline & $\begin{array}{l}20 \\
09\end{array}$ & $\begin{array}{l}20 \\
10\end{array}$ & $\begin{array}{l}20 \\
11\end{array}$ & $\begin{array}{l}20 \\
12\end{array}$ & $\begin{array}{l}20 \\
13\end{array}$ & $\begin{array}{l}20 \\
14\end{array}$ & $\begin{array}{l}20 \\
15\end{array}$ & $\begin{array}{l}20 \\
16\end{array}$ & $\begin{array}{l}20 \\
17\end{array}$ & $\begin{array}{l}20 \\
18\end{array}$ \\
\hline LC & MI & MI & $\mathrm{O}$ & $\mathrm{O}$ & $\mathrm{O}$ & $\mathrm{O}$ & $\mathrm{O}$ & $\mathrm{O}$ & $\mathrm{O}$ & $\mathrm{O}$ \\
\hline $\mathrm{G}$ & & & VI & VI & VI & VI & VI & VI & VI & VI \\
\hline NA & MI & $\mathrm{O}$ & MI & $\mathrm{O}$ & $\mathrm{O}$ & $\mathrm{O}$ & $\mathrm{O}$ & $\mathrm{O}$ & $\mathrm{O}$ & $\mathrm{O}$ \\
\hline $\mathrm{Y}$ & & VI & & VI & VI & VI & VI & VI & VI & VI \\
\hline HE & $\mathrm{O}$ & $\mathrm{O}$ & $\mathrm{O}$ & $\mathrm{C}$ & $\mathrm{C}$ & $\mathrm{C}$ & $\mathrm{C}$ & $\mathrm{C}$ & $\mathrm{C}$ & $\mathrm{C}$ \\
\hline UA & VI & VI & VI & TS & TS & TS & TS & TS & TS & TS \\
\hline GP & $\mathrm{O}$ & $\mathrm{O}$ & $\mathrm{O}$ & $\mathrm{O}$ & $\mathrm{O}$ & $\mathrm{O}$ & $\mathrm{O}$ & $\mathrm{O}$ & $\mathrm{O}$ & $\mathrm{O}$ \\
\hline UA & VI & VI & VI & VI & VI & VI & VI & VI & VI & VI \\
\hline $\mathrm{JC}$ & $\mathrm{O}$ & $\mathrm{O}$ & $\mathrm{O}$ & $\mathrm{O}$ & $\mathrm{O}$ & $\mathrm{O}$ & $\mathrm{O}$ & $\mathrm{O}$ & $\mathrm{C}$ & $\mathrm{O}$ \\
\hline $\mathrm{G}$ & VI & VI & VI & VI & VI & VI & VI & VI & TS & VI \\
\hline $\mathrm{CC}$ & $\mathrm{O}$ & $\mathrm{O}$ & $\mathrm{O}$ & $\mathrm{O}$ & $\mathrm{O}$ & $\mathrm{O}$ & $\mathrm{O}$ & C & C & C \\
\hline G & VI & VI & VI & VI & VI & VI & VI & TS & TS & TS \\
\hline SU & C & $\mathrm{C}$ & $\mathrm{C}$ & $\mathrm{C}$ & $\mathrm{C}$ & $\mathrm{C}$ & $\mathrm{C}$ & $\mathrm{C}$ & $\mathrm{C}$ & C \\
\hline AY & TS & TS & TS & TS & TS & TS & TS & TS & TS & TS \\
\hline
\end{tabular}

\section{System development optimization}

The high-quality development of the Yellow River Basin is inseparable from the ecological protection of urban agglomerations. Environmental pollution, economic fluctuations and resource waste hinder the improvement of coordination. Through the analysis of factors and their weights, combined with the specific development of urban agglomerations in the river basin, the following suggestions are given:

1. The quantitative index system for ecological protection and high-quality development of the Yellow River Basin and the calculation results of the weights of various factors (Table 1) show that in the economic development subsystem, the degree of dependence on foreign trade and economic volatility account for larger weights. The authorities should make full use of the level and quality of foreign investment, make overall plans for both opening up and domestic development, and form a new pattern of two-way opening to promote river basin economic development, reduce economic volatility, and increase dependence on foreign trade gradually. In the ecological environment subsystem, the newly added water and soil erosion control area and wetland area account for a larger weight in the area under the jurisdiction this year. The concept of green development should be upheld, and the beach area should be encouraged to provide more ecological products and carry out ecological compensation for beach area residents.

2. The synergy degree of subsystems calculation results s of the Yellow River Basin urban agglomeration in 2018 (Table 2) show that there are significant spatial differences in the ecological protection and high-quality development synergy of the Yellow River Basin urban agglomeration and its subsystems. The ecology and economy of the urban agglomerations in the river basin are complex and diverse in space, with obvious differences in characteristics. Therefore, a differentiated strategy should be adopted for the specific geographical environment, resource advantages and synergy level of each urban agglomeration.

3. The coordination degree between urban agglomerations in the Yellow River (Figure 1) shows that the regional coordination of urban agglomerations in the basin is not close, and top-level design planning should be done. The authorities need to speed up the construction of expressway network and communication network, and build a transportation network connected by river basins. Breaking the dual structure of urban and rural areas should be undertaken immediately, and manage water resources in the Yellow River Basin, strengthening the management of sewage outlets into the river and water function zones is also vital. The government need to establish a communication platform, and build a cross-regional cooperation mechanism with deep participation of enterprises to strengthen coordination. Dock between urban agglomerations, and give full play to the advantages of regional cooperation, and form a perfect inter-regional market system.

\section{Conclusions}

This paper analyzes the coordination degree of ecological protection and high-quality development of urban agglomerations in the Yellow River Basin, and it can more closely describe the coordination characteristics of ecological protection and high-quality development of urban agglomerations in the basin, the conclusions are as follows:

( 1 ) Ecological Restoration feature layer in the ecological environment subsystems, water resources element layer subsystem of economic development in the economic base layer elements and the relationship between man and water subsystem, both ecological protection and development of high quality in the right number of heavy elements of the Yellow River Basin.it shows that ecological destruction, economic fluctuations and water waste are the main factors hindering the improvement of synergy.

(2) There are significant spatial differences in the ecological protection and high-quality synergy of urban 
agglomerations in the Yellow River Basin and their subsystem development indexes. The ecological protection and high-quality synergy of the river basin urban agglomerations generally shows gradually decreasing cascade distribution pattern from east to west, from downstream to upstream. Among the urban agglomerations in the middle and lower reaches, the Guanzhong Plain urban agglomeration and the Jinzhong urban agglomeration are significantly lower than the Shandong along the Yellow River urban agglomeration in the east and the Hubao-Eyu urban agglomeration in the west, and the Central Plains urban agglomeration is in the middle.

(3) Urban agglomerations with high synergy also have weaknesses, and urban agglomerations with low synergy also have strengths. The economic development index of Hubao-Egyu urban agglomeration, which ranks second overall, has become its shortcoming and constraint; The Central Plains urban agglomeration, Guanzhong Plain urban agglomeration and Jinzhong urban agglomeration, which are ranked third, fourth and fifth overall, need to improve their ecological environment and human-water relationship development index.

(4) The level of coordinated development of various urban agglomerations is steadily improving, and the difference in the level of coordinated development of various urban agglomerations is gradually decreasing. In 2009, only Shandong's urban agglomeration along the Yellow River with a degree of synergy greater than 0.5 , in a "close to synergy" state, and most of the remaining urban agglomerations are in a state of "on the verge of imbalance"; by 2018, Shandong urban agglomeration along the Yellow River, the Central China urban agglomeration and Hubao-Eyu urban agglomeration and the Central Plains urban agglomeration have reached a state of "close to synergy", and the remaining four urban agglomerations are about to reach a state of "close to synergy".

\section{References}

1. Xi J. (2019) Speech at the Symposium on Ecological Protection and High-quality Development of the Yellow River Basin. J. Qiushi, 20:4-11.

2. Shi B. (2020) The era connotation and realization path of the high-quality development of the Yellow River Basin. J. Theoretical Vision, 09: 61-66.

3. Ren B, Du Y. (2021) Research on ecological protection and high-quality development strategy in the middle reaches of the Yellow River. J. People's Yellow River, 43(2):1-5.

4. Ma H, Xu L. (2020) High-quality development assessment and spatial pattern differentiation of urban agglomerations in the Yellow River Basin J. Economic Geography, 40(4): 11-18.

5. Shao P, Wang Q, Shan Y. (2020) Research on ecological protection and high-quality development of the Yellow River Basin based on text analysis J. Arid Land Resources and Environment, 34(11): 7883.
6. Zhao R. (2020) The key to ecological protection and high-quality development in the Yellow River Basin: the optimization of the man-land system J. Arid Land Resources and Environment, 41(3):1-6.

7. Liu K, Ren J, Zhang B. (2019) Evolution characteristics and influencing factors of the vulnerability of the human-land system in the Yellow River Delta J. Economic Geography, 21(2):135-145.

8. Lu D. (2002) Theoretical research on the "humanland system" of geography J. Geographical Research, 21(2): 135-145.

9. Liu Y. (2020) Modern man-land relationship and man-land system science J. Geographical Science, 40(8): 1221-1234.

10. Li X, Yang Y, Liu Y. (2017) Research progress in man-land relationship evolution and its resourceenvironment base in China J. Journal of Geographical Sciences, 20: 899-924.

11. Zhang C, Li Z, Dong X, et al. (2014) Analysis of the level of agricultural development in the BRICS countries-a comparative study based on the entropy weight method and the coefficient of variation method J. Science and Technology and Economy, 27(162): 42- 46.

12. Xue L, Yang Y, Chen L, et al. (2020) The Yellow River Basin Ecological Protection and High-quality Development Strategy Legislation Strategy, J. Science and Technology and Economy, 30(12):1-7. 